\title{
CROWDSOURCING - KONSEKWENCJE DLA RYNKU PRACY ARTYSTÓW
}

\section{Abstract \\ Crowdsourcing - consequences for artists' labour market}

Internet essentially stimulates the way the labour market has been transforming. It makes it possible to mobilize the crowds of web users to work or collaborate on a project differently than conventional organisations used to do. The paper looks at crowdsourcing as a mechanism that gives widespread flexibility of labour conditions and of the types of workers. In particular it discusses the key changes within the artists' labour market at the time of the growing fame of the Internet including the crowdsourcing cases.

Keywords: crowdsourcing, labour market, artists, Internet

\section{Streszczenie}

Internet w sposób fundamentalny wpływa na transformację uwarunkowań rynków pracy. Potrafi mobilizować tłumy internautów do pracy czy współpracy inaczej, niż czyniły to tradycyjne organizacje. W artykule uwagę zwrócono na crowdsourcing jako mechanizm dający powszechną elastyczność warunków pracy. W szczególności omówiono najważniejsze kierunki zmian dla rynku pracy artystów w dobie rosnącej popularności internetu, w tym praktyk crowdsourcingowych.

Słowa kluczowe: crowdsourcing, rynek pracy, artyści, internet

\section{Wprowadzenie}

Kształt rynku pracy artystów jest pochodną myślenia systemowego o modelu kultury w danym kraju. Dominujący element publicznego profilowania polityki kulturalnej - obecny w krajach europejskich, w tym również w Polsce jest w sposób widoczny oparty na bardzo dużym zaangażowaniu państwa i samorządów w procesy jej projektowania oraz realizowania [Ilczuk, 2012: 44]. Znaczący udział państwa w wyznaczaniu warunków i prowadzeniu polityki 
kulturalnej jest związany z przyjętym poziomem interwencjonizmu państwa w wybrane sfery życia społeczno-gospodarczego [Cultural Policy..., 1969: 10-11], na co w naturalny sposób wpływ mają historyczne uwarunkowania [Golinowska, 1994]. Kultura jest obszarem chętnie włączanym do kanonu celów wspieranych przez państwa. Niejednokrotnie w dyskusjach na temat uzasadniania wspierania kultury przez państwo podnoszone są argumenty z zakresu zarządzania publicznego, $\mathrm{w}$ tym m.in. teoria dóbr publicznych [Samuelson, 1954], teoria dóbr merytorycznych [Musgrave, 1959] czy wręcz dyżurna teoria Williama Baumola i Williama Bowena [1966] o tzw. chorobie kosztów [krytyczne ujęcie zob. np. Cowen, 1996].

Jeśli chodzi o sam rynek pracy artystów, jest on w Polsce w wysokim stopniu poddany deregulacji. Największy wpływ na sytuację pracujących artystów ma popyt [Ilczuk, 2012; Ilczuk, 2013; Zawadzki, 2016]. Oznacza to, że jest to rynek nabywcy, który niejednokrotnie stoi przed wyzwaniem odróżnienia świetnie wypromowanego produktu od wysokiej jakości dobra kultury. Wycena dokonywana przez nabywcę często pozbawiona jest obiektywizmu lub nie jest merytoryczna, raczej polega na uleganiu osobistym preferencjom konsumpcyjnym. Szczegółowe badania rynku pracy artystów pokazały wyraźne luki w polityce państwa odnoszące się zarówno do kwestii podażowych (szkolnictwo artystyczne), jak i popytowych (skala wsparcia bezpośredniego dla artystów, ulgi podatkowe, poziom edukacji kulturalnej) [Ilczuk i in., 2015]. Autorzy badania konkluduja, że „zawodowa sytuacja twórców i artystów w Polsce nie jest adekwatna do rozpoznanych tendencji rozwojowych, zgodnie z którymi kultura i jej przemysły zostały uznane za nowy obszar inwestowania, źródło kreatywności i innowacyjności" [Ilczuk, 2013: 21]. Co ciekawe, autorzy badania widzą dużą rolę państwa w stymulowaniu rynku pracy artystów i twórców w Polsce, m.in. przez wprowadzenie narzędzi pobudzania popytu na dzieła artystów, edukację kulturalną czy wdrażanie systemowych rozwiązań w zakresie zabezpieczenia zawodowego i socjalnego artystów i twórców.

Obecnie jednym ze źródeł zmian w zakresie rynku pracy jest internet, który sprzyja uczestnictwu w wirtualnych projektach o charakterze zarówno zarobkowym, jak i bezpłatnym. Konwencjonalne rynki pracy zarządzane są przez decydentów politycznych, kształtowane przez prawo pracy, układy zbiorowe pracy, lokalne normy. Ale ekonomia platform pośredniczących i świadczących prace jest inna, bowiem to właściciele platform dyktują warunki m.in. co do wysokości wynagrodzenia. Coraz więcej przedsiębiorstw biznesowych korzysta z platform świadczących pracę online (online labour platforms), by mieć dostęp do wyspecjalizowanych pracowników i ich umiejętności, oczekując ponadto elastyczności i oszczędności wydatków. Stąd i ogromna popularność portali zorientowanych na świadczenie różnych typów pracy, od niewielkich mikrozadań do złożonych projektów technologicznych i usług profesjonalnych. Dziesiątki milionów pracowników szuka pracy za pośrednictwem tych platform, dla niektórych stają się one źródłem zarobków, ponieważ niskie bariery uczestnictwa i egalitarne zasady pracy zachęcają do działania [The iLabour Project]. Rynek pracy artystów i twórców - choć w mniejszym wymiarze niż biznes - poddany 
zostaje dyktatowi wirtualizacji pracy. Właśnie crowdsourcing jako proces jest jednym z wielu narzędzi technologicznych wpływających na zmiany w obrębie rynków pracy w tym zakresie.

Celem niniejszego artykułu jest wskazanie konsekwencji płynących z popularyzacji działań crowdsourcingowych w odniesieniu do rynku pracy artystów. Pierwsza część tekstu wyjaśnia zjawisko crowdsourcingu oraz pokazuje na przykładach wykorzystanie tego mechanizmu do realizacji projektów w obszarze kultury. W kolejnej części artykułu wskazano główne cechy charakteryzujące obecnie rynek pracy artystów. Dalej omówiono najważniejsze kierunki zmian dla tego rynku w dobie rosnącej popularności internetu, w tym praktyk crowdsourcingowych. Ponieważ artykuł jest pomyślany jako materiał opisujący pewne zjawiska, opiera się głównie na analizie literatury przedmiotu.

\section{Crowdsourcing w kulturze}

Crowdsourcing to neologizm zaproponowany przez Jeffa Howe'a [2006] w artykule The Rise of Crowdsourcing. Robiące zawrotną karierę pojęcie (28 października 2017 roku uzyskałam aż 131 tys. wskazań w Google Scholar i 37,2 mln wskazań w Google) zbudowane zostało na kanwie angielskich słów crowd (tłum) i outsourcing (delegowanie) [Howe, 2006]. Tłumaczenia tego terminu na język polski spotykane w literaturze (np. „mądrość tłumów”, „mądrość zbiorowa”) nie są adekwatne, stąd znaczna popularność tego terminu w języku angielskim. Sam termin „crowdsourcing” jest bardzo szeroki i definiuje się go na przynajmniej kilka sposobów [Estellés-Arolas, González-Ladrón-de-Guevara, 2012]. W crowdsourcingu chodzi o realizację przez tłum internautów zadania zleconego odgórnie przez organizatora projektu. Rozwiązując zadanie, internauci otrzymują za swoją pracę wynagrodzenie finansowe lub pozafinansowe (m.in. rozpoznawalność w środowisku, poczucie własnej wartości) [Brabham, 2010, 2013]. Zlecone zadania obejmują szeroki zakres usług, m.in. produkcję wiedzy, treści, elementów audio i wideo [Brabham, 2011].

Pojawiający się w kontekście crowdsourcingu termin „tłum” stwarza wiele problemów w rozumieniu tego zjawiska, głównie z powodu położenia akcentu na jednoczesną aktywność ogromnej rzeszy anonimowych internautów. W rzeczywistości jednak w projektach crowdsourcingowych zazwyczaj nie obserwuje się uczestnictwa na masową skalę, czego przykładem jest polski projekt Otwarte Zabytki [zob. online Otwarte Zabytki] czy brytyjski What's the Score at the Bodleian? [zob. online What's the Score at the Bodleian?]. Oczywiście znane i popularne są masowe projekty tzw. nauki obywatelskiej (citizen science, people-powered-research), znajdujące się głównie w portfolio brytyjskiej platformy Zooniverse [Zooniverse.org].

Zasadniczo mechanizm crowdsourcingu nie jest zjawiskiem wcześniej nieznanym. W literaturze przedmiotu pisze się o prosumpcji, z której wyrósł crowdsourcing korzystający z medium, jakim jest internet. Termin ,,prosumpcja” wiąże 
się z futurystyczną wizją Alvina Tofflera z Trzeciej fali. Według niego obecna tzw. trzecia fala poprzemysłowa, którą wyróżnia rewolucja informatyczna, cechuje się zacieraniem się funkcji produkcji i konsumpcji. Toffler nazwał ten proces prosumpcją [Toffler, Toffler, 2006]. Charakteryzuje go hasło „Zrób to sam”, znajdujące też swe odzwierciedlenie w różnych formach samoobsługi (np. wprowadzana od lat 20. XX wieku samoobsługa w sklepach, dynamiczna popularyzacja od lat 50. sieci restauracji typu fast food, a także popularny w sektorze meblarskim od lat 70. ruch „Zrób to sam”, którego pionierem była IKEA; wpisuje się tu także np. samodzielne rezerwowanie biletów na podróż czy do teatru, zamawianie książek lub dokonywanie przelewów bankowych). Zasadnicza idea polega na tym, że klienci sami muszą się włączyć w proces wytwarzania dóbr i ich dystrybucji [Voß, Rieder, 2005].

\section{Specyfika rynku pracy artystów}

Naukowcy zajmujący się badaniami rynku pracy artystów podkreślają m.in. następujące właściwości tego rynku [Towse, 2011; Hesmondhalgh, 2007; Menger, 2001; Ross, 2009, Zawadzki, 2016; Frank, Cook, 1996]:

- artyści podejmują więcej niż jedną pracę - tzw. zatrudnienie równoległe (multiple job holders),

- artyści samozatrudnieni czy tzw. niezależni stanowią grupę dominująca,

- pracę artystyczną cechuje nieregularność (co wiąże się głównie z nagminną praktyką zawierania kontraktów krótkookresowych na wykonanie danego zadania, niezapewniających przy tym żadnego systemu ochrony pracy),

- perspektywy kariery artystycznej są niepewne (pojawia się wysokie ryzyko kariery zakończonej niepowodzeniem) i nie kształtują się liniowo (ścieżka awansu nie jest w żaden sposób zdefiniowana),

- występuje duże rozwarstwienie w wysokości zarobków artystów, a szerzej: istnieje przepaść między płacami tych, którzy osiągnęli sukces, i tych, którym się nie powiodło (sytuacja typowa dla tzw. społeczeństwa, w którym zwycięzca bierze wszystko - The-Winner-Takes-All-Society).

Tymczasem zapotrzebowanie na produkty artystyczne wydaje się zależne od co najmniej kilku podstawowych czynników, np. potencjalnych dochodów publiczności czy jej wcześniejszych doświadczeń ze sztuką [Throsby, Thompson, 1995]. Świat sztuki jest środowiskiem hybrydowym, pełnym paradoksów, w którym łączy się tradycjonalizm z wymogami przedsiębiorczości [Mathieu, 2012]. Sektor kultury i sztuki jest dodatkowo wyjątkowo zależny od wsparcia publicznego, które z kolei często faworyzuje określone grupy beneficjentów (np. twórców dzieł o charakterze konserwatywnym kosztem autorów dzieł o charakterze eksperymentalnym), co więcej, jego priorytety uzależnione są od szerszych założeń polityki kulturalnej [Frey, 2003]. Znaczenie tego wsparcia jest tym większe, że stosunkowo niewielki procent przedsięwzięć artystycznych okazuje się rentowny, trudno również przewidzieć, czy artystyczny produkt stanie się „hitem” [Hodsoll, 2002]. 


\section{Crowdsourcing a rynek pracy artystów}

Nowe kanały komunikacyjne na nowo definiują logikę wchodzenia artystów na rynek pracy $\mathrm{i}$ ich na nim funkcjonowania w przynajmniej kilku wymiarach.

Crowdsourcing może wpływać na zmiany w zakresie wynagradzania artystów i twórców na rynku pracy.

Howard Becker [1982] twierdzi, że praca artysty jest wpisana w system relacji społecznych - opiera się na współpracy wielu osób i jej ocena poddana jest wielu pozaestetycznym kryteriom, takim jak uzasadnienie symboliczne. Dlatego też kwestia wynagrodzenia artystów jest niezwykle złożona.

Rynek pracy artystów jest określany jako wyjątkowy [Abbing, 2002]. Średnie zarobki w obszarze sztuki są niższe niż innych pracowników o porównywalnym edukacyjnym i demograficznym profilu, artyści doświadczają też dłuższych okresów bezrobocia [Throsby, Hollister, 2003]. Są jednak gotowi pracować za niskie wynagrodzenie, w niepełnym wymiarze godzin lub łączyć pracę artysty z pracą dodatkową w innej dziedzinie, żeby tylko móc funkcjonować jako artysta [Papandrea, Albon, 2004].

Kamil Zawadzki [2016] w swoich badaniach poświęconych pracy i wynagrodzeniom w gospodarce kreatywnej wyróżnił dychotomiczny model czynników decydujących o wejściu na ten rynek pracy. Zdaniem badacza implikuje on inny sposób transmisji wykształcenia i doświadczenia na uzyskiwane wynagrodzenie. Na pierwszej ścieżce zawodowej obowiązują wysokie bariery wejścia, jeśli chodzi o wymagany poziom formalnego wykształcenia (architektura, dziedzictwo kulturowe, edukacja artystyczna, sektor naukowo-nadawczy, muzyka klasyczna). Na ścieżce drugiej dychotomicznego modelu czynników wejścia na kreatywny rynek pracy formalne wykształcenie nie przynosi istotnego wzrostu dochodów (np. rzemieślnicy artystyczni, muzycy nieklasyczni, artyści wizualni, twórcy gier komputerowych, graficy, copywriterzy). Tu barierami wejścia na rynek pracy gospodarki kreatywnej są przede wszystkim talent, odpowiednia osobowość, determinacja, odporność na stres, a w pewnej mierze także czynnik losowy. Crowdsourcing właśnie dla pracowników w tym drugim modelu może stać się narzędziem wchodzenia na rynek pracy.

Jedną z konsekwencji popularyzacji pracy crowdsurcingowej jest brak prawnych regulacji tego typu zatrudnienia. Nie istnieje żadna prawna czy socjalna ochrona interesów pracowników i pracodawców [Kreft, 2014]. Należy jednak zaakcentować dobrowolność crowdsourcingu - zarówno w zakresie przekazania zadania do realizacji przez dany podmiot, jak i wykonania zadania przez internautów. Jak zauważa Wiesława Caputa [2016: 42], dane zlecenie ma „,charakter prośby, a nie stosunku prawnego, z którego mogą wynikać jakiekolwiek konsekwencje prawne". Z tego względu wykonawca zadania nie może żądać wynagrodzenia, a zlecający może je ustalać, ale nie musi.

Jan Kreft przyznaje, że ,,zadania wykonywane na platformach crowdsourcingowych są na ogół znacznie więcej warte, niż sugerują wypłacane za nie wynagrodzenia/nagrody. Dotyczy to takich platform, jak Stockphoto czy InnoCentive i wielu innych" [Kreft, 2014: 48]. Stąd też częste zaangażowanie w zadania 
crowdsourcingowe amatorów, którzy pracę dla danej firmy czy marki uznają za duże wyróżnienie, nie oczekując zapłaty finansowej. Również artyści są w stanie przyjąć niskie lub nawet symboliczne wynagrodzenia, gdy dany projekt czy zadanie stanowi dla nich inwestycję w przyszłość [Dąbrowska, 2014]. Przykładem takiego podejścia było do niedawna także wystawianie prac w państwowych instytucjach kultury, które nie przynosiło żadnego dochodu. W 2014 roku Obywatelskie Forum Sztuki Współczesnej wywalczyło symboliczne opłaty - minimum $3700 \mathrm{zł}$ za wystawę indywidualną, $800 \mathrm{zł}$ za udział w wystawie zbiorowej [Dąbrowska, 2014]. Zaangażowanie w pracę opiera się w przypadku artystów na pasji i przywiązaniu do pewnego stylu bycia i tożsamości przypisywanej zwykle tego typu pracownikom kreatywnym. Tę tożsamość określa zazwyczaj m.in. nieformalne środowisko pracy i przedsiębiorczość, której towarzyszy strach o pracę zarobkową oraz o bieżącą aktualizację umiejętności na szybko zmieniających się polach aktywności [Banks, 2007; McRobbie, 2016; Neff i in., 2005; Ross, 2009].

Crowdsourcing z pewnością stwarza też pewnego rodzaju zagrożenie dla firm korzystających z tego rozwiązania. Jest nim utrata kontroli nad powierzonym zadaniem i sposobem, w jaki jest ono wykonywane, bowiem osoba wykonująca daną pracę nie ponosi za nią odpowiedzialności, co wyraźnie różni ją od pracownika zatrudnionego formalnie. Przed niskąjakością wykonania zadania crowdsourcingowego zabezpieczają zleceniodawców tzw. klauzule zadowolenia, pozwalające odrzucić wyniki prac [Kreft, 2014].

Crowdsourcing może wpływać na nadpodaż artystów na rynku pracy: „W wielu zawodach gospodarki kreatywnej występuje permanentna nadwyżka podaży pracy nad popytem na nią" [Zawadzki, 2016: 226]. Na tym rynku można zauważyć wyraźną nierównowagę, której nie są w stanie przeciwdziałać mechanizmy samego rynku. Kamil Zawadzki powołuje się na Adama Smitha, który twierdził, że osób piśmiennych i uczonych jest bardzo dużo, co prowadzi do obniżania ceny za ich pracę do marnej zapłaty [Zawadzki, 2016: 226]. Nadpodaż wysoko wykwalifikowanych specjalistów na rynku pracowników kreatywnych powoduje sytuację, w której początkujący gotowi są za niskie stawki podejmować pracę u uznanych mistrzów, którzy następnie sprzedają dzieła przygotowane przez „praktykantów” z zyskiem [Zawadzki, 2016: 226-227].

Omawiana nadpodaż wynika przynajmniej z kilku czynników. Po pierwsze przyczyną jest duża popularność kierunków artystycznych wśród polskich studentów, zwłaszcza w pierwszej dekadzie XXI wieku. Zgodnie z danymi GUS w latach 2002-2014 [za: Zawadzki, 2016: 228-229] liczba absolwentów kierunków artystycznych wzrosła ponad trzykrotnie. W rezultacie udział absolwentów kierunków artystycznych w ogólnej liczbie absolwentów uczelni wzrósł z 0,7\% w 2002 do 1,8\% w 2014 roku. Co ciekawe, wzrost zainteresowania kształceniem na kierunkach artystycznych odnotowano zarówno na uczelniach publicznych, jak i niepublicznych (w 2014 roku ukończyło je 4,5 razy więcej osób niż w 2004). W sumie w roku akademickim 2014/2015 na wszystkich kierunkach artystycznych kształciło się w Polsce 36,5 tys. osób, w tym w wyższych szkołach artystycznych 17,3 tys., z czego z kolei 3 tys. osób (17,4\%) na uczelniach niepublicznych. Najbardziej popularne artystyczne kierunki studiów o dużym potencjale 
rynkowym to grafika (7,1 tys. studentów), wzornictwo (3,6 tys. studentów) i architektura wnętrz (3,5 tys. studentów) [Zawadzki, 2016: 228-229].

Współcześnie mamy więc do czynienia z paradoksalną sytuacją, w której mimo wysokiego odsetka absolwentów kierunków artystycznych obserwuje się niskie znaczenie dyplomu w budowaniu kariery: doświadczenie i reputacja są tu dużo bardziej cenione (zjawisko to jest coraz częściej zauważane w odniesieniu do absolwentów kierunków pozaartystycznych [zob. Sennett, 2006, 2010]). Ponieważ dyplomy nie mają decydującego znaczenia w procesie budowania kariery, niskie bariery wejścia zachęcają osoby o zróżnicowanym wykształceniu do spróbowania sił na tej ścieżce zawodowej. David Throsby i Beverley Thompson [1995] dowiedli tej prawidłowości na przykładzie artystów z obszaru sztuk wizualnych. Takie uwarunkowania pracy kreatywnej oznaczają, że na rynkach pracy jest coraz więcej pracy nieregularnej, niepewnej i bez zabezpieczenia socjalnego [Hesmondhalgh, 2007].

Proces demokratyzacji profesjonalnego statusu artysty w internecie wpływa na rozszerzenie znaczenia tradycyjnie rozumianych zawodów artystycznych na amatorów - użytkowników internetu czy hobbystów [Bruns 2010; Ritzer, Jurgenson, 2010]. Artystami stają się często osoby bez wykształcenia artystycznego czy bez innego przygotowania zawodowego, piszące w sieci różne relacje (pisarze?) czy dokumentujące wydarzenia w formie fotografii (fotografowie?).

Crowdsourcing z pewnością wpływa na silniejsze niż dotychczas zacieranie się różnic między artystami profesjonalnymi a artystami amatorami. Kiedyś pojęcia te stanowiły dla siebie wzajemnie antytezę, teraz często trudno je od siebie oddzielić. Richard Sennett wykazuje, że do podstawowych składowych profesjonalnej działalności artystycznej należy talent oraz kunszt rozumiany jako wręcz rzemieślnicze dążenie do doskonałości [Sennett, 2010: 84]. Procesy internetyzacji pracy, w tym crowdsourcing, nie sprzyjają rozwojowi kunsztu wśród artystów zmuszonych stawić czoła zmieniającym się uwarunkowaniom pracy. Obserwujemy obecnie bardzo częste podejmowanie prac przez internet, czemu służą znaczące obniżenie barier wejścia w danych rodzajach działalności oraz egalitarne zasady uczestnictwa. Stąd i rosnący udział tzw. profesjonalnych amatorów (,pro-amów”), którzy mogą się dzielić rezultatami swojej pracy z fanami czy subskrybentami [Leadbeater, Miller, 2004]. Zacieranie się różnic między amatorami a profesjonalistami jest też rezultatem rozwoju cyfrowych narzędzi kreatywnych (np. pakiet Adobe Creative Suite), które obok zaawansowanej funkcjonalności wymaganej przez profesjonalnych twórców są łatwe w obsłudze dla amatorów [Składanek, 2010].

Crowdsourcing może również zmieniać rozumienie sukcesu w przypadku karier artystycznych. Poziom sukcesu jest wartością mocno zsubiektywizowaną [Arthur i in., 2005] - jednostki same wyznaczają ścieżkę kariery wedle indywidualnych reguł i zasad. W ramach tak zdefiniowanych postorganizacyjnych ścieżek ,karier bez granic" (boundaryless career) [Arthur, Rousseau, 1996] osiągnięcie sukcesu jest wysoce sprzężone z indywidualnymi predyspozycjami do zarządzania swoją karierą. Crowdsourcing, pozwalając na udział w różnego rodzaju projektach, stwarza właśnie duże możliwości takiego zarządzania, a także kreowania własnych projektów. Dzięki takim działaniom artyści kształtują swoje portfolio, również 
własną reputację, która może gwarantować pozyskiwanie zleceń czasowych na rynku pracy. Throsby i Thompson [1995] zauważyli korelację między liczbą zrealizowanych projektów czy zleceń a poprawą reputacji - im więcej bowiem dany artysta podjął zleceń, tym wyżej oceniana była jego reputacja.

Crowdsourcing pozwala ponadto na zaangażowanie internautów w proces tworzenia. Oznacza to publiczną partycypację w kreowaniu dzieł sztuki. W rezultacie zacierają się granice między twórcą a odbiorcą dzieła. Na zacieranie granic pomiędzy profesjonalnymi twórcami a konsumentami kultury wpływają niskie bariery wejścia do świata społeczności online, jak również egalitarne reguły działania w projektach internetowych.

\section{Podsumowanie}

Popularyzacja internetu jako narzędzia pracy (i płacy) artystów wpływa na rozproszenie tego specyficznego rynku pracy. Te zjawiska w oczywisty sposób nie ograniczają się tylko do rynku pracy artystów, lecz mają znacznie szerszy zasięg - można powiedzieć, że są one syntezą współczesnej gospodarki. Dlatego też ważna staje się analiza przekształceń w zakresie znaczenia i uwarunkowań pracy artystów pod wpływem narzędzi internetowych, w tym crowdsourcingu. Konsekwencje wynikające $\mathrm{z}$ wykorzystania mechanizmu crowdsourcingu poddane są dyskusji, bowiem mają one bezpośredni wpływ na społeczno-ekonomiczne wyzwania w obszarze kształtowania rynku pracy artystów.

Crowdsourcing oddziałuje na sposób, w jaki dobra kultury są wytwarzane, dystrybuowane i konsumowane. Ten kanał komunikacyjny na nowo definiuje logikę funkcjonowania artystów na rynku pracy w przynajmniej kilku wymiarach m.in. może wpływać na zmiany w zakresie wynagradzania artystów i twórców na tym rynku. Może ponadto odgrywać dużą rolę w nasilaniu się nadpodaży artystów na rynku pracy.

\section{Bibliografia}

Abbing H. (2002), Why Are Artists Poor? The Exceptional Economy of the Arts, Amsterdam University Press, Amsterdam.

Arthur M., Khapova S., Wilderom C. (2005), Career Success in a Boundaryless Career Worlds, „Journal of Organizational Behavior”, 26(2), Special Issue: Reconceptualizing Career Success.

Arthur M., Rousseau D. (1996), The Boundaryless Career: A New Employement Principle for a New Organizational Era, Oxford University Press, Oxford.

Banks M. (2007), The Politics of Cultural Work, Palgrave Macmillan, New York.

Baumol W., Bowen W. (1966), Performing Arts, the Economic Dilemma: A Study of Problems Common to Theater, Opera, Music and Dance, MIT Press, Michigan. 
Becker H. (1982), Art Worlds, University of California Press, Berkeley.

Brabham B. (2010), Moving the Crowd at Threadless: Motivations for Participation in a Crowdsourcing Application, „Information, Communication \& Society”, 13(8).

Brabham D. (2011), Myth of Amateur Crowds, „Information, Communication and Society”, 15(3).

Brabham D. (2013), Crowdsourcing, The MIT Press, Cambridge (Mass.)-London.

Bruns A. (2010), News Produsage in a Pro-Am Mediasphere: Why Citizen Journalism Matters, http://snurb.info/files/2010/News\%20Produsage\%20in\%20a\%20Pro-Am\%20Mediasphere.pdf [dostęp: 30.10.2017].

Caputa W. (2016), Bariery w wykorzystaniu crowdsourcingu na potrzeby budowania kapitału klienta, „Zeszyty Naukowe Politechniki Śląskiej. Organizacja i Zarządzanie”, 96.

Cowen T. (1996), Why I Do Not Believe in the Cost-Disease: Comment on Baumol, „Journal of Cultural Economics", 20(3).

Cultural Policy: A Preliminary Study (1969), UNESCO, Paris.

Dąbrowska M. (2014), Stan badań nad sytuacja finansowq artystów. Historia sztuki a ekonomiczne aspekty pracy artystów, Obserwatorium Kultury w Gdańsku, http://obserwatorium.ikm.gda.pl/artykul/malgorzata-dabrowska-stan-badan-nad-sytuacja-finansowa-artystow-historia-sztuki-a-ekonomiczne-aspekty-pracy-artystow-przeglad-historyczny/ [dostęp: 25.05.2018].

Estellés-Arolas E., González-Ladrón-de-Guevara F. (2012), Towards an Integrated Crowdsourcing Definition, „Journal of Information Science”, 38(2).

Frank R., Cook Ph. (1996), The-Winner-Takes-All-Society: Why the Few at The Top Get So Much More Than the Rest of Us, Penguin Books, New York.

Frey B. (2003), Arts and Economics: Analysis and Cultural Policy, Springer, Berlin.

Golinowska S. (1994), Polityka spoleczna państwa w gospodarce rynkowej. Studium ekonomiczne, Wydawnictwo Naukowe PWN, Warszawa.

Hesmondhalgh D. (2007), Creative Labour as a Basis for a Critique of Creative Industries Policy [w:] G. Lovink, N. Rossiter (eds.), My Creativity Reader: A Critique of Creative Industries, Institute of Network Cultures, Amsterdam.

Hodsoll F. (2002), Cultural Transactions, „Journal of Arts Management, Law and Society”, 32(2).

Howe J. (2006), The Rise of Crowdsouring, „Wired Magazine”, 14(6), 1-4.

The iLabour Project, Investigating the Construction of Labour Markets, Institutions and Movements on the Internet, The Oxford Internet Institute, http://ilabour.oii.ox.ac.uk/ [dostęp: 30.10.2016].

Ilczuk D. (2012), Ekonomika kultury, Wydawnictwo Naukowe PWN, Warszawa.

Ilczuk D. (red.) (2013), Rynek pracy artystów i twórców w Polsce. Raport z badań, Fundacja Pro Cultura, SWPS, Bydgoszcz-Warszawa.

Ilczuk D., Dudzik T., Gruszka E., Jeran A. (2015), Artyści na rynku pracy, Biblioteka Zarządzania Kulturą, t. 16, Wydawnictwo Attyka, Kraków.

Kreft J. (2014), Crowdsourcing - darmowe źródło ustug w mediach [w:] M. Pluta-Olearnik, S. Wrona (red.), Ustugi 2014. Wybrane uwarunkowania rozwoju ustug, Prace Naukowe Uniwersytetu Ekonomicznego we Wrocławiu, 354, Wydawnictwo Uniwersytetu Ekonomicznego, Wrocław.

Leadbeater Ch., Miller P. (2004), The Pro-Am Revolution: How Enthusiasts Are Changing Our Economy and Society, Demos, http://www.demos.co.uk/files/proamrevolutionfinal. pdf [dostęp: 30.10.2017]. 
McRobbie A. (2016), Be Creative: Making a Living in the New Culture Industries, Polity Press, Malden.

Mathieu Ch. (ed.) (2012), Careers in Creative Industries, Routledge, Oxon.

Menger P.M. (2001), Artists as Workers: Theoretical and Methodological Challenges, „Poetics”, 28(4).

Musgrave R.A. (1959), The Theory of Public Finance: A Study in Public Economy, McGraw-Hill, New York.

Neff G., Wisinger E., Zukin S. (2005), Entrepreneurial Labor Among Cultural Producers: “Cool Jobs in Hot Industries”, ,Social Semiotics”, 15(3).

Papandrea F., Albon R. (2004), A Model of Employment in the Arts, „Australian Economic Papers", 43(3).

Ritzer G.J., Jurgenson N. (2010), Production, Consumption, Prosumption: The Nature of Capitalism in the Age of the Digital "Prosumer”, ,Journal of Consumer Culture”, 10(1).

Ross A. (2009), Nice Work If You Can Get It: Life and Labour in Precarious Times, New York University Press, New York-London.

Samuelson P.A. (1954), The Pure Theory of Public Expenditure, „The Review of Economics and Statistics", 36(4).

Sennett R. (2006), Korozja charakteru. Osobiste konsekwencje pracy w nowym kapitalizmie, tłum. J. Dzierzgowski, Ł. Mikołajewski, Muza, Warszawa.

Sennett R. (2010), Kultura nowego kapitalizmu, tłum. G. Brzozowski, K. Osłowski, Muza, Warszawa.

Składanek P. (2010), Kreatywność i współdziałanie w epoce cyfrowej. Praktyki, społeczności, przestrzenie i narzędzia [w:] P. Zawojski (red.), Digitalne dotknięcia. Teoria w praktyce. Praktyka $w$ teorii, Make It Funky Production, Szczecin.

Throsby D., Hollister V. (2003), Don't Give Up Your Day Job: An Economic Study of Professional Artists in Australia, Macquarie University, Sydney.

Throsby D., Thompson B. (1995), The Artists at Work: Some Further Results from the 1988 Survey of Individual Artists, Australia Council, Sydney.

Toffler A., Toffler H. (2006), Revolutionary Wealth, Knopf Doubleday Publishing Group, New York.

Towse R. (2011), A Handbook of Cultural Economics, 2nd Edition, Edward Elgar, Cheltenham-Northampton.

Voß G., Rieder K. (2005), Der arbeitende Kunde. Wenn Konsumenten zu unbezahlten Mitarbeitern werden, Campus Verlag, Frankfurt am Main.

Zawadzki K. (2016), Praca i wynagrodzenia w gospodarce kreatywnej. Uwarunkowaniaspecyfika-ewolucja, Wydawnictwo Naukowe UMK, Toruń.

\section{Strony internetowe}

Otwarte Zabytki, http://otwartezabytki.pl/ [dostęp: 30.10.2017].

What's the Score at the Bodleian?, http://www.bodleian.ox.ac.uk/bodley/finding-resources/ special/projects/whats-the-score [dostęp: 30.10.2017].

Zooniverse.org, https://www.zooniverse.org [dostęp: 30.10.2017]. 